\title{
Sistem Panel Kinerja Untuk Program Studi Sarjana Berbasis BAN PT
}

\author{
Agus Prasetyo Utomo ${ }^{\mathrm{a}^{*}}$, Ibnu Widiyanto ${ }^{\mathrm{b}}$ \\ ${ }^{a}$ Fakultas Teknologi Informasi, Universitas Stikubank \\ ${ }^{\mathrm{b}}$ Magister Manajemen, Fakultas Ekonomika dan Bisnis, Universitas Diponegoro
}

Naskah Diterima : 10 Januari 2013; Diterima Publikasi : 30 Maret 2013

\begin{abstract}
Study program need to do monitoring and continuously measurements of performance to ensure achievement the goals set of its. The process of performance requires monitoring data and information was taken from all parts of the organization. The purpose of this research is to build a panel system performance (performance dashboard) that can be used to help measure the performance of undergraduate degree courses based on BAN PT in order of quality assurance in higher education. The results of performance monitoring will be delivered to the parties concerned, efficiently and effectively. Panel System (Dashboard) is a tool to present information at a glance. Dashboard inform using Key Performance Indicators (KPI) an effective presentation media. KPIs are used in the construction panel system performance of these courses entirely using the instruments of the National Accreditation of Higher Education. The methodology can be applied either on a case study of the development of dashboards to support the efforts of quality assurance courses at the Stikubank University Semarang. This study emphasizes how the application is to provide easy information to Head of study program, Dean of faculty, Rector and Vice Rector of university to the achievement of the quality of undergraduate study program.
\end{abstract}

Keywords: Performance dashboard; Key performance indicators; Accreditation

\section{Abstrak}

Program studi perlu melakukan monitoring dan pengukuran secara terus-menerus terhadap kinerjanya untuk memastikan ketercapaian tujuan yang telah ditetapkan. Proses monitoring kinerja memerlukan data dan informasi yang diambil dari seluruh bagian organisasi. Hasil monitoring kinerja selanjutnya akan disampaikan kepada pihak-pihak yang berkepentingan, secara efisien dan efektif.Sistem Panel (Dashboard) merupakan alat untuk menyajikan informasi secara sekilas . Dashboard menginformasikan Key Performance Indicators(KPI) dengan menggunakan media penyajian yang efektif. KPI yang digunakan dalam pembangunan sistem panel (Dasboard) kinerja program studi ini seluruhnya menggunakan instrumen dari Badan Akreditasi Nasional (BAN) perguruan tinggi. Metodologi yang digunakan dapat diterapkan dengan baik pada studi kasus mengenai pembangunan dashboard untuk menunjang upaya penjaminan mutu program studi di lingkungan Universitas Stikubank Semarang. Penelitian ini lebih menitikberatkan bagaimana aplikasi ini bisa memberikan kemudahan informasi terhadap pengelola program studi, fakultas maupun pihak universitas terhadap capaian mutu dari program studi sarjana.

Kata kunci: Akreditasi; Sistem panel kinerja; Indikator kunci kinerja

\section{Pendahuluan}

Pentingnya pengukuran kinerja tidak hanya diperlukan dan dilakukan dalam dunia bisnis tetapi juga dalam dunia pendidikan. Demikian pentingnya pengukuran kinerja dalam pengelolaan perguruan tinggi atau dunia pendidikan, maka direktorat jenderal pendidikan tinggi memasukkannya dalam format manajemen baru yang bertujuan untuk meningkatkan kualitas pendidikan secara berkelanjutan yaitu dengan membentuk Badan Akreditasi Nasional (BAN).

Universitas Stikubank sebagai sebuah perguruan tinggi sangatlah perlu untuk membentuk Sistem Penilaian Kinerja demi terciptanya visi dan misi *) Penulis korespondensi : agusprasetyo@gmail.com sebagai bagian dari sistem penjaminan mutu. Sistem penilaian kinerja yang baik haruslah terintegrasi untuk semua unit dan aktivitas di perguruan tinggi. Indikator kinerja yang terbentuk tidak hanya berupa indikator kinerja finansial (keuangan) tetapi juga indikator kinerja nonfinansial.

Pengelolaan dan penyajian informasi bukanlah hal yang mudah, mengingat kompleksitas dan banyaknya informasi yang dimiliki organisasi. Organisasi memerlukan sebuah sistem untuk mengelola informasi dan menyajikannya dalam bentuk yang efisien dan efektif. Efisien berarti bahwa informasi tersebut dapat dipahami dengan mudah dan cepat oleh penerimanya. Sedangkan efektif berarti bahwa 
makna yang terkandung dalam informasi tersebut dapat dipersepsi dengan baik dan benar oleh penerimanya, sehingga tujuan dari penyampaian informasi tersebut dapat tercapai.

Sistem panel (dashboard) merupakan alat untuk menyajikan informasi secara sekilas, solusi bagi kebutuhan informasi organisasi (Few, 2006). Sistem Panel (dashboard) mengumpulkan informasi yang relevan dari berbagai bagian organisasi, mengkonsolidasikan, dan menyampaikannya secara aman, cepat, dengan personalisasi sesuai dengan peran pengguna dalam organisasi. Metoda sistem panel kinerja (performance dashboard) adalah suatu alat bantu yang dapat mengkomunikasikan suatu kinerja dengan menampilkan informasi terpilih yang ditampilkan secara visual sehingga kita dapat dengan cepat menemukan dimana letak dari suatu permasalahan, sehingga dapat segera pula dilakukan langkah pengambilan keputusannya.

Tujuan dari penelitian ini adalah bagaimana membangun sistem panel kinerja (performance dashboard) yang dapat digunakan untuk membantu pengukuran kinerja program studi jenjang sarjana berbasis BAN PT dalam rangka jaminan mutu di lingkungan perguruan tinggi Universitas Stikubank Semarang.

\section{Kerangka Teori}

\subsection{Pengukuran Kinerja}

Dalam kehidupan sehari-hari kita sering melakukan pengukuran, namun dalam penelitian, untuk melakukan pengukuran harus memenuhi syarat-syarat tertentu. Pengukuran dalam penelitian terdiri dari pemberian angka-angka pada peristiwa empiris sesuai dengan aturan-aturan tertentu (Cooper dan Emory, 1996).

Dalam perancangan suatu sistem manajemen kinerja terdapat 4 tahap dalam perancangan sistem manajemen kinerja (Wibisono, 2006):

a. Tahap 0 : Fondasi

Pemahaman atas pedoman prinsip yang harus

dijadikan fondasi bagi rancangan sistem manajemen kinerja.

b. Tahap 1 : Informasi Dasar

Informasi dasar yang diperlukan sebagai masukan bagi perancang sistem manajemen kinerja pada dasarnya menyangkut lingkungan usaha yang saat ini sedang digeluti, yang terdiridari informasi tentang industri, pemerintah dan masyarakat, pasar dan pesaing, serta produk dan jasa yang dihasilkan perusahaan.

c. Tahap 2 : Perancangan

Merupakan lankah perancangan sistem manajemen kinerja yang terdiridari penentuan visi, misi, strategi, dan kerangka kerja yang digunakan sebagai dasar penentuan variabel kinerja, keterkaitan antar variabel, dan kaji banding (bencmark) yang akan diambil.

d. Tahap 3: Penerapan

Merupakan tahap penerapan rancangan yang meliputi display yang akan didukung, laporan yang akan dirancang, sosialisasi sistem manajemen kinerja kepada seluruh karyawan, analisis manfaat/biaya bagi penerapan sistem manajemen kinerja, modifikasi proses yang diperlukan, pelatihan yang harus disertakan, sumber daya yang akan terlibat, dan kedudukan sistem manajemen Kinerja saat ini terhadap sistem manajemen kinerja yang baru. Pada saat penerapan, harus diuji apakah sistem manajemen kinerja tersebut telah dapat mengakomodasi 4 hal utama, yaitu pengukuran, evaluasi, diagnosis, dan tindak lanjut yang diperlukan jika kinerja perusahaan menyimpang dari standar yang telah ditetapkan.

e. Tahap 4 : Penyegaran

Merupakan langkah evaluasi terhadap kemutakhiran Sistem manajemen kinerja yang dirancang dengan mempertimbangkan informasi dan perkembangan pengetahuan terkini.

\subsection{Sistem Panel Kinerja (Performance Dashboard)}

Dashboard adalah alat bantu kontrol untuk mengidentifikasi jalannya proses bisnis secara mudah dengan menggunakan indikatorindikator tertentu seperti misalnya penggunaan indikator warna-warna khusus yaitu merah, hijau atau kuning yang melambangkan status atau kondisi dari suatu bisnis atau proyek, tanda peringatan, ringkasan-ringkasan, grafik-grafik seperti bar-chart, pie chart, dimana biasanya dibuat satu set dalam suatu portal, dan dapat diatur.

Performance Dashboard memiliki fungsi yang lebih dari hanya sekedar grafik-grafik performansi, performance dashboard adalah suatu bussines information sistem yang komplit yang dibangun dari bussines intelegent dan struktur data yang terintegrasi, dimana performance dashboard ini menampilkan mekanisme-mekanisme display dengan mudah. Istilah information dashboard didefinisikan sebagai tampilan visual dari informasi penting, yang diperlukan untuk mencapai satu atau beberapa tujuan, dengan mengkonsolidasikan dan mengatur informasi dalam satu layar (single screen), sehingga kinerja organisasi dapat dimonitor secara sekilas. Tampilan visual disini mengandung pengertian bahwa penyajian informasi harus dirancang sebaik mungkin, sehingga mata manusia dapat menangkap informasi secara cepat dan otak manusia dapat memahami maknanya secara benar (Few, 2006). 
Definisi Performance Dashboard (Sistem Panel Kinerja) menurut Eckerson adalah aplikasi yang dibangun berdasarkan business intelligence dan terintegrasi dengan data yang digunakan organisasi untuk mengukur, memonitor, dan mengatur business performance agar dapat berjalan lebih efektif (Eckerson, 2006).

Gambaran umum sebuah arsitektur sistem panel kinerja dapat dilihat pada Gambar 1.

Simplified Dashboard Architecture

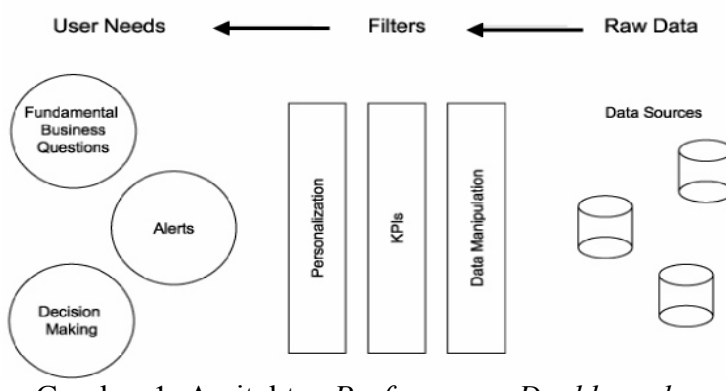

Gambar 1. Arsitektur Performance Dashboard

(Kirtland, 2003)

\section{Metodologi}

Data yang digunakan dalam penelitian ini adalah berupa data kuantitatif yang dikumpulkan untuk mengidentifikasi dan menyusun Key Performance Indikator (KPI) sebagai dasar dari pembentukan desain performance dashboard, dan data untuk menyusun usulan dari desain performance dashboard itu sendiri. Data yang diperlukan untuk menyusun desain Performance Dashboard adalah data primer dihasilkan dari wawancara dengan kepala lembaga penjaminan mutu, dan data sekunder berupa profil lembaga, job description, instrumen akreditasi program studi sarjana yang memiliki 7 standard penilaian dengan 100 butir penilaian.

Kerangka pikir penelitian untuk pengembangan sistem panel kinerja (performance dashboard) diberikan dalam sebuah diagram alur. (Gambar 2).

Metodei pembangunan dashboard memiliki 7(tujuh) tahapan utama, sesuai dengan tahapan dalam pengembangan sistem perangkat lunak, yaitu identifikasi kebutuhan, perencanaan, perancangan prototype, review prototype, implementasi, deployment, dan maintenance. Pada peneitian ini hanya dibahas tiga tahapan yang pertama, yaitu identifikasi kebutuhan, perencanaan, dan perancangan prototype.

\section{Hasil dan Pembahasan}

\subsection{Identifikasi Masalah}

Dari hasil identifikasi didapat bahwa permasalahan terletak pada belum adanya sistem pengukuran kinerja program studi dalam bentuk sistem panel (dashboard) yang ditujukan secara khusus sesuai dengan standar Badan Akreditasi Nasional (BAN) perguruan tinggi. Sehingga untuk melakukan monitoring dan evaluasi kinerja program studi secara tidak langsung masih dilakukan secara manual oleh semua pihak yang berkepentingan terhadap kinerja program studi di lingkungan universitas.

\subsection{Pengumpulan dan Analisis Data}

Pengumpulan dan analisis data berupa instrumen akreditasi program studi sarjana dari Badan Akreditasi Nasional (BAN) perguruan tinggi yang merupakan pokok dari penelitian ini. Pengumpulan data tersebut dikumpulkan untuk mengidentifikasi dan menyusun key performance indikator (KPI) sebagai dasar dari pembentukan desain performance dashboard, dan data untuk menyusun usulan dari desain performance dashboard itu sendiri.

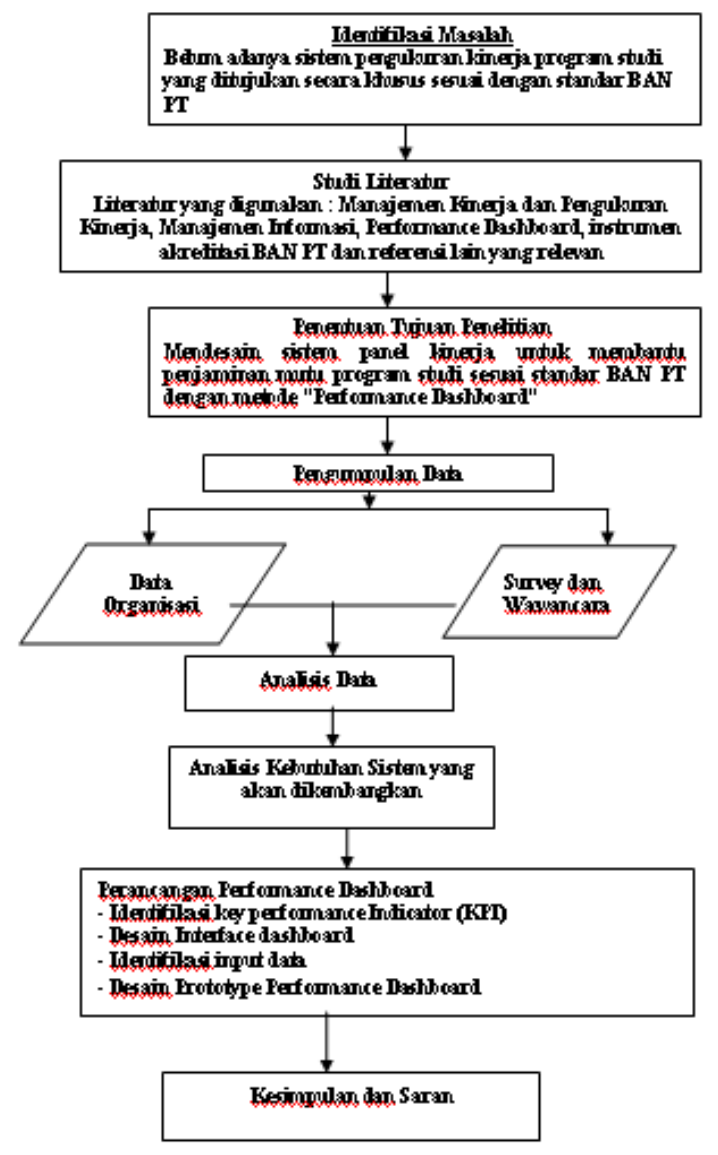

Gambar 2. Jalannya Penelitian

\subsection{High-level Scenario Dashboard}

Identifikasi high-level scenario dashboard dilakukan melalui wawancara dengan pimpinan lembaga penja,in mutu (LePenMu) Unisbank Semarang, yaitu ketua Lepenmu Dari hasil wawancara dapat 
diperoleh tujuan dan lingkup pembangunan dashboard. Jenis dashboard yang dibuat adalah strategic dan tactical dashboard.

Gambaran umum dari sistem panel kinerja dapat di gambarkan ke dalam Arsitektur sistem panel kinerja (dashboard). Arsitektur tersebut dapat dilihat pada Gambar 3.
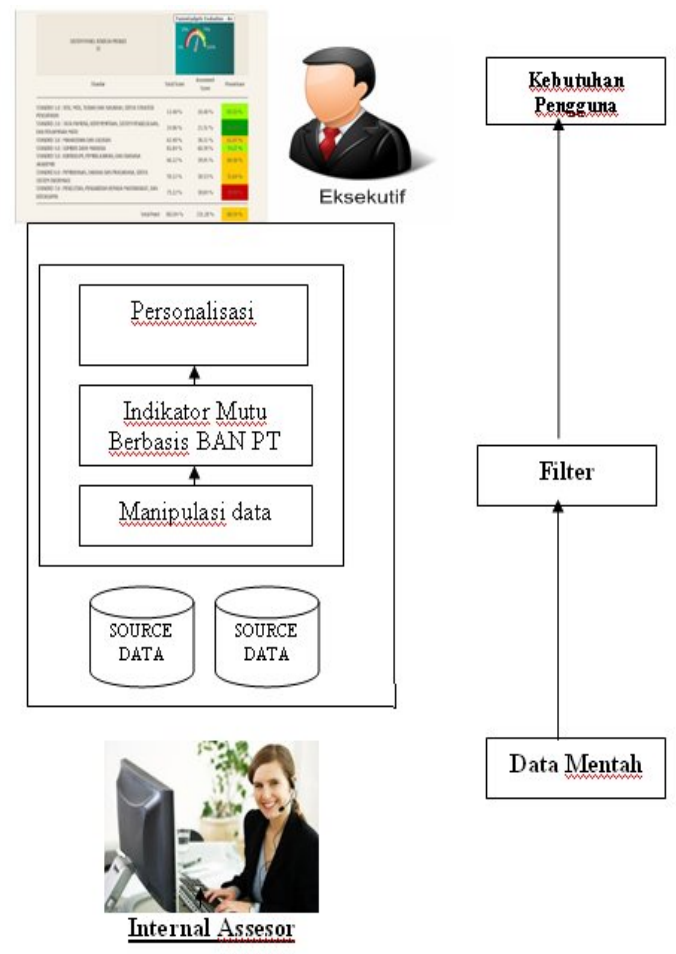

Gambar 3. Arsitektur sistem panel kinerja program studi

Halaman utama menampilkan informasi yang ditampilkan secara ringkas namun menyeluruh. Dalam halaman ini merupakan informasi ringkas berkaitan hasil penilaian kinerja mutu dari semua program studi yang ada. Halaman ini hanya bisa di akses oleh Rektor, Pembantu Rektor 1 sd 4, Lepenmu, Dekan dan LPPM. Hasil Tampilan halaman utama dapat dilihat pada Gambar 4.

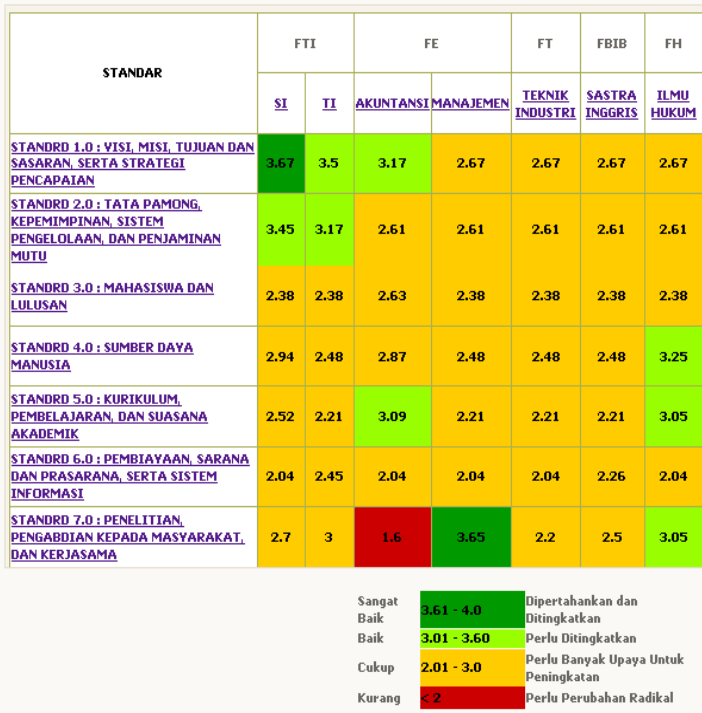

Gambar 4. Halaman utama sistem panel kinerja program studi

\subsection{Halaman Sistem Panel Kinerja Program Studi}

Halaman ini menampilkan dashboard untuk capaian kinerja program studi sesuai program studi masing-masing, halaman ini bisa diakses oleh Rektor, Pembantu Rektor 1 sd 4, dan LPPM, Dekan fakultas dan Program studi. Hasil Tampilan halaman ini dapat dilihat pada Gambar 5.
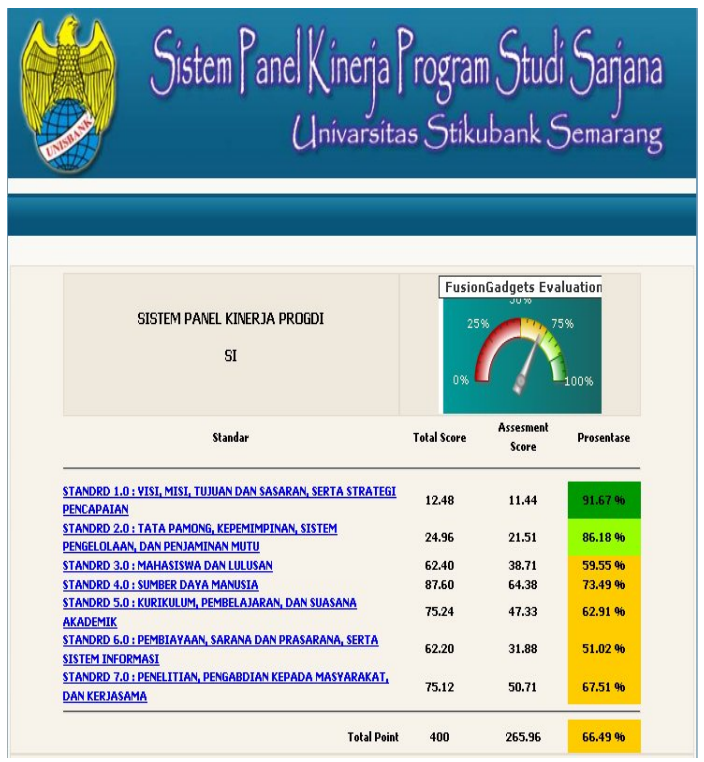


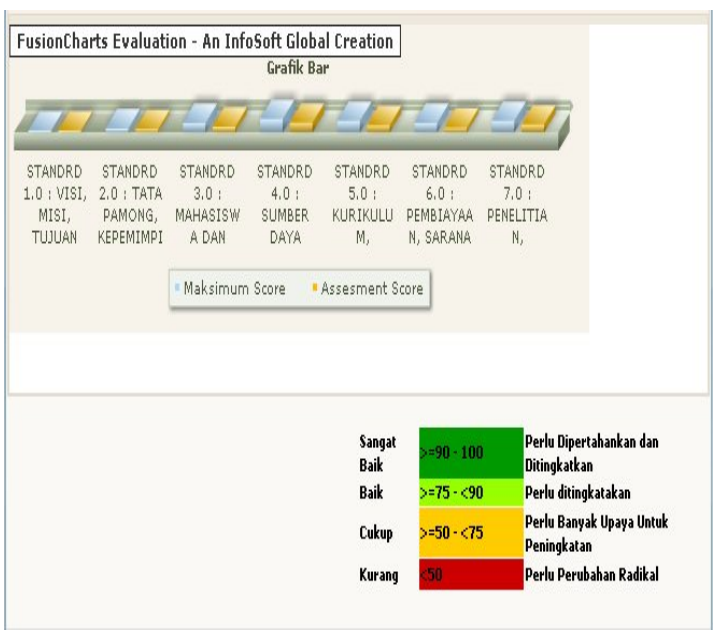

Gambar 5. Halaman sistem panel kinerja program Studi

Halaman ini menampilkan dashboard untuk detail key performance indikator untuk standar 1 sampai standar 7 sesuai program studi masing-masing. Hasil Tampilan halaman ini dapat dilihat pada Gambar 6.

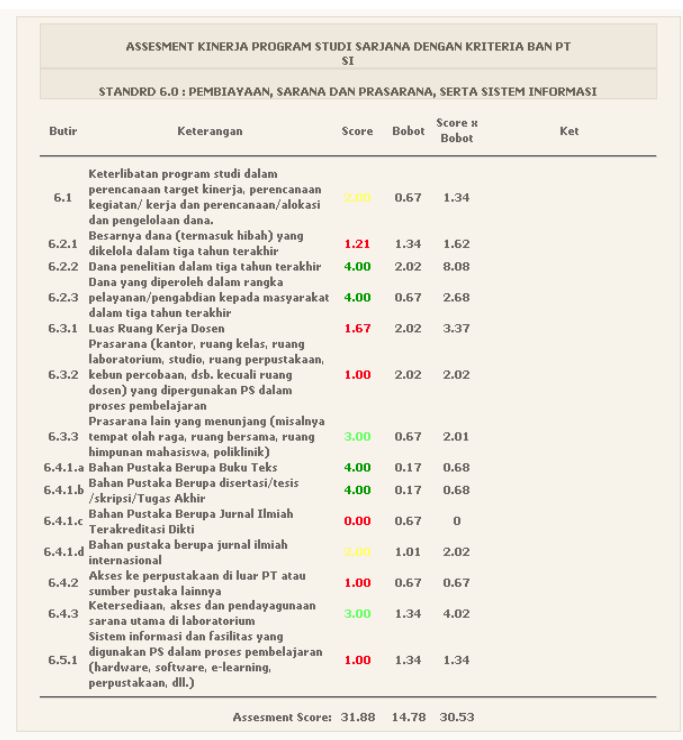

Gambar 6. Halaman sistem panel kinerja detail program studi

\section{Kesimpulan}

Sistem Panel (Dashboard) yang digunakan dalam penelitian ini sesuai dengan kebutuhan pengguna, karena semua indikator yang digunakan berdasar pada instrument akreditasi dari Badan Akreditasi Nasional (BAN) perguruan tinggi, dengan cara tersebut setidaktidaknya akan memberikan gambaran yang jelas dari waktu ke waktu kepada manajemen baik itu di jajaran pejabat struktural universitas maupun fakultas di universitas Stikubank Semarang berkaitan dengan pencapaian mutu setiap program studi sesuai standar yang telah ditetapkan oleh BAN. Metodologi dapat diterapkan dengan baik pada studi kasus mengenai pembangunan sistem dashboard untuk menunjang upaya penjaminan mutu program studi di lingkungan universitas. Data yang mendukung indikator-indikator memiliki frekuensi update satu tahun sekali dikarenakan internal assesment dilakukan per tahun. Dapat dikatakan bahwa data yang digunakan tersebut tidak terlalu real time, sehingga perubahan nilai-nilai indikator pada sistem panel (dashboard) juga tidak terlalu sering. Untuk dashboard dengan jenis strategic dan tactical dashboard, data dengan karakteristik yang tidak terlalu real-time tersebut masih cocok untuk digunakan.

\section{Daftar Pustaka}

Cooper, D.R., Emory, C.W., 1996. Metode Penelitian Bisnis, Erlangga.

Eckerson, W., 2006. Deploying Dashboard and Scorecard, TDWI best practice report.

Eckerson, W., 2006. Performance Dashboards: Measuring, Monitoring, and Managing Your Business. New Jersey: John Wiley\&Sons.

Few, S., 2006. Information Dashboard Design, O'Reilly.

Harel, E.C., Sitko, T.D., 2003. Buletin Center For Applied Research, Volume 2003, issue 19, September 16, 2003.

Kaplan, R.S. dan Norton, D.P., 1996. The Balanced Scorecard: Translating Strategy into Action, Harvard Business School Press, Boston, Massachusetts.

Kirtland, A., 2003. Executive Dashboard, Website: http://www.boxesandarrows.com/view/executive dashboards, diakses tanggal 10 Febuary 2012.

Wibisono, D., 2006. Manajemen Kinerja: Konsep, Desain, Teknik Meningkatkan Daya Saing Perusahaan, Penerbit Erlangga, Jakarta. 